\section{BRUXISM AND POST-TRAUMATIC STRESS}

S4S, the specialist dental splints laboratory and exclusive provider of NTI-tss - a device used in the limitation and control of bruxism - will be launching the first Bruxism Awareness Week on 25-31 October at this year's Dental Showcase.

Bruxism Awareness Week will aim to highlight bruxism, a condition that affects up to 50\% of the UK population, and encourage more dental practices to offer effective treatment. The week will be supported by a practice information pack that is free to all UK practices.

The NTI-tss is made by practition- ers in the surgery and snaps into place to fit comfortably on the upper or lower front teeth. It is worn during sleep and reduces the intensity of muscular parafunction.

$\mathrm{S} 4 \mathrm{~S}$ is also involved in raising awareness of the link between Post Traumatic Stress Disorder (PTSD) and bruxism in the armed forces and is offering free training to military dentists.

S4S will also be showcasing a groundbreaking new technology called GRINDCARE at Dental Showcase. Visit them at stand D10.

Reader response number 55

\title{
INCREASE EFFICIENCY AND PROFITABILITY
}

At this year's BDTA Dental Showcase delegates can look forward to witnessing Denticom's solutions to practice efficiency and profitability.

Call management identifies missed calls. Messages promoting your practice's services can be played free of charge and patients are informed of their place in the queue. Missed calls are lost potential revenue.

Denticom 24/7 ensures you do not miss a call even when you are closed. Denticom answers the call for you.

Patient Check In is a multi-lingual touch screen enabling your patients to check themselves in for their appointments, alleviating congestion on reception.

Patient Pop is unique to Denticom. It identifies patients when they call and answers personally with their name.

Patient Info Point enables you to sell your services and treatment effectively with a touch screen kiosk and TV screen (where the content is hosted and therefore updated every 20 minutes).

Visit Denticom on stand V28 to find out how the above systems can be provided to your practice for zero capital investment. Some practices are also eligible for additional funding.

Reader response number 56

\section{INNOVATION IN ENDODONTICS AND RESTORATIVES}

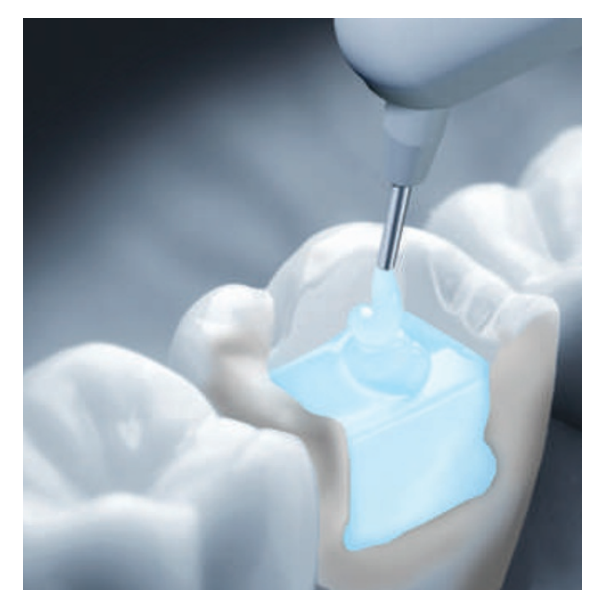

On Dentsply's stand at BDTA Dental Showcase delegates will have the opportunity to explore their innovative new endodontic and restorative products, including Smart Dentin Replacement (SDR).

Dentsply's dentists and experienced team will be on hand to demonstrate how to use the new products in each range. An area especially dedicated to product promotions will also be available where clinicians will find excellent offers on popular items such as ProTaper and other endodontic equipment, Cavitron units and inserts, and Ash instruments.

In addition, visitors can find out about the Dentsply Academy's new CPD programmes, including educational events, webinars, 'How to Guides' and online learning packages.

Go to stand D01.

Reader response number 58

\section{GET RAPID LONG-LASTING RELIEF}

Visitors to this year's BDTA Dental Showcase will be offered a sample of new Sensodyne Rapid Relief.

Recent research highlights that when the strontium acetate formula of Sensodyne Rapid Relief is massaged on to the base of a sensitive tooth for 60 seconds, patients get rapid relief from their sensitivity. Long-lasting protection from sensitivity can be achieved by brushing twice a day with the product.

GlaxoSmithKline Consumer Healthcare (GSK) staff will be on stand J10 to answer any questions about their full product range which also includes Aquafresh, Corsodyl, Sensodyne Pronamel and Poligrip. Reader response number 59 